\title{
NUANÇAS DA PAIXÃO NA MEDEIA DE EURÍPIDES
}

\author{
NUANCES OF PASSION IN EURIPIDES' MEDEA
}

Andrelino Ferreira dos Santos Filho*

\begin{abstract}
RESUMO
A Medeia de Eurípides é uma das mais importantes peças do teatro antigo. A complexidade do texto e a fertilidade das possibilidades interpretativas tem despertado grande interesse dos estudiosos. Neste artigo, pretendo analisar algumas noções que compõem o núcleo do irracional tipificado na protagonista (Medeia). Trata-se de demonstrar a insuficiência do emprego do termo pathos para qualificar o comportamento da personagem no drama. $\mathrm{O}$ problema consiste nas parcas ocorrências do referido vocábulo para sustentar o sentido do que seja agir pelo irracional. A fim de ampliar a compreensão do que rege as cenas marcadas por forças irracionais, serão levadas em consideração as noções de ódio e cólera/ira, entre outros. Para proceder a análise textual, foram utilizadas três traduções em português, a saber, a tradução de Mário da Gama Kury, a tradução de Jaa Torrano e a tradução de Maria Helena da Rocha Pereira, além do texto grego publicado pela editora ateniense Kaktoz.
\end{abstract}

PALAVRAS-CHAVE: Medeia. Tragédia. Irracional. Ira.

\section{ABSTRACT}

Euripides' Medea is one of the most important plays of ancient theater. The complexity of the text and the fertility of interpretive possibilities has aroused great interest among scholars. In this article, I intend to analyze some notions that make up the core of the irrational typified in the protagonist (Medea). This is to demonstrate the inadequacy of the use of the term pathos to qualify the behavior of the character in the drama. The problem consists in the few occurrences of pathos to sustain the meaning of what is to act by the irrational. In order to broaden the understanding of what governs scenes marked by irrational forces, notions of hatred and anger, among others, will be taken into account. To proceed with the textual analysis, three Portuguese translations are used. They are: the translation of Mário da Gama Kury, the translation of Jaa Torrano and the translation of Maria Helena da Rocha Pereira, and also, the Greek text published by the Athenian Kaktoz publisher.

KEYWORDS: Medea; Tragedy; Irrational; Anger.

\section{INTRODUÇÃO}

A Medeia de Eurípides é definitivamente uma das mais importantes peças produzidas pelo teatro grego clássico, e talvez não seja exagero afirmar o mesmo grau de relevância no que tange ao teatro ocidental em termos gerais. A força dessa afirmação pode ser aferida pela

\footnotetext{
${ }^{*}$ Doutor em Estudos Literários - FALE/UFMG; Doutor em Filosofia - FAFICH/UFMG; Professor de Filosofia na PUC Minas e na Universidade do Estado de Minas Gerais. e-mail: andrelinofilho@ yahoo.com.br.
} 
quantidade de trabalhos sobre a referida peça teatral, especialmente os esforços de investigação sob a inspiração de Maria Helena da Rocha Pereira. Nesse sentido, destaca-se tanto a frente de pesquisa levada a cabo pelo Instituto de Estudos Clássicos da Universidade de Coimbra quanto os trabalhos do Departamento de Filologia Clássica da Universidade de Valladolid, numa estreita e fértil colaboração.

Estudos como os desenvolvidos por Fialho (2006), que mostram a articulação entre elementos políticos e éticos são certamente indispensáveis, assim como a perspectiva rigorosamente filológica através da qual Férez (2006) estabelece a relação entre a linguagem e os sentimentos da protagonista da peça (Medeia). Leão (2006), por sua vez, enfatiza a situação jurídica sob a qual Eurípides coloca o drama, enquanto Salamanca (2006) analisa a conduta da referida personagem a partir de critérios socrático-platônicos. Não menos importante é o estudo realizado por Cidre (1998), que estabelece a noção de cólera como o princípio-motor do comportamento de Medeia.

Como se vê, são muitas as interpretações acerca do estatuto da ação de Medeia, demonstrando o grau de dificuldade para definir, de forma isenta de contestações, o que rege a protagonista. Com efeito, a personagem provoca em muitos estudiosos a tentação de reduzi-la a uma figura racional, bárbara, deusa, modelo de resistência feminista, etc. Por outro lado, uma leitura reducionista sempre gera quase que imediatamente alguma compreensão antitética, o que pode ser exemplificado pela oposição à dimensão racional da ação da protagonista e as passagens textuais que indicam ações dominadas pelas paixões.

Nos limites dessas considerações, não é meu intuito discutir as diversas possibilidades interpretativas, de modo a explicitar as ambiguidades que a figura de Medeia comporta. Tratase de discutir tão somente a pertinência da hipótese de que o móbil que orienta a ação em questão é a paixão, mas não no sentido de uma oposição à Medeia "racional" - por assim dizer.

O mito do qual se serve Eurípides consiste em relato oriundo de tempos remotos. A versão encenada por Eurípides tem como gênese o encontro/casamento entre Medeia (uma mulher bárbara) e Jasão (um homem grego). Jasão, depois de ter chegado à região da Cólquida para reclamar o velocino de ouro, exigência para assumir o poder em Iolco, teve de enfrentar desafios diversos como critério para obtenção da posse do tosão sagrado. Sob a intervenção da deusa Hera, que a partir de uma articulação com Eros deita profunda paixão no coração de Medeia, Jasão recebe a ajuda necessária para o êxito no cumprimento das tarefas, quais sejam, (1) arar um campo com dois monstruosos e indomáveis touros de cascos de 
bronze, os quais expeliam fogo pelas narinas; (2) semear no campo arado os dentes de um dragão que fora morto por Cadmo em tempos passados, o que seria impossível senão pela decisiva ajuda de Medeia; (3) combater uma seara de soldados nascidos dos dentes do dragão; e, por fim, (4) enfrentar o guardião do tosão de ouro (um temível monstro). Vale ressaltar que na fuga mais uma vez a intervenção da habilidosa Medeia é importante, quando adota como estratégia de fuga (com o futuro marido) o homicídio de seu irmão, esquartejando-o e lançando as partes no mar para atrasar a perseguição que sabia que aconteceria. E, quando da chegada em Iolco, a saga da feiticeira continua, pois a ela é imputada a responsabilidade pela morte de Pélias (o rei usurpador do trono). Numa espécie de fusão entre magia e astúcia, Medeia faz-se amiga das filhas do rei e promete rejuvenescer o velho tirano. Para provar, depositou dentro de um caldeirão um carneiro velho e esquartejado, retirando em seguida o animal inteiro e em perfeita saúde. Convencidas pela prova, as filhas esquartejaram o pai e procederam da mesma forma que Medeia o fizera, mas sem o resultado esperado. Foi esse acontecimento que teria motivado a fuga do casal para Corinto - onde efetivamente o drama se desenrola.

Claro está que, em face ao mito, não resta dúvida acerca da paixão que move Medeia. Não quer dizer que a personagem não se sirva de expedientes racionais para atingir determinadas metas - como já demonstrei noutra ocasião ${ }^{1}$. Mas, seria correta a afirmação de que efetivamente a ação é movida pelo paixão em face de apenas duas parcas ocorrências do vocábulo pathos? Além disso, tais passagens (versos 692 e 754) não autorizam nenhuma inferência acerca do estatuto da ação de Medeia, pois trata-se de referências à recepção de uma ação ou aos efeitos de uma ação (adikei m Iason ouden ex emou pathon = lesa-me Jasão, quando de mim nada sofreu; arkei ti d orko tode me mmenon pathois = basta! Não mantendo esta jura, que sofrerias?). Então, em que sentido é possível considerar a paixão como mola propulsora da ação da princesa cólquida? Com efeito, a resposta exige a articulação de diversos termos que compõem o núcleo semântico da ação patética, quais sejam, as noções de coração (kardia), fígado (epathos), vísceras (fren), cólera (hepar), ódio (echthra), ira e ardor (cholos e orge).

Para levar a cabo a discussão, lançarei mão de três traduções da peça, a saber, os trabalhos de Mário da Gama Kury, de Maria Helena da Rocha Pereira e de Jaa Torrano. A versão de Torrano (por ser bilíngue - grego/português) e a publicação do texto grego pela editora ateniense Kaktoz servirão de parâmetro para dirimir impasses que possam surgir do

\footnotetext{
${ }^{1}$ Sapere Aude - Belo Horizonte, v.2 - n.4, p.59-75- 2o sem. 2011.
} 
cotejo das edições na língua portuguesa. Para facilitar o manejo das traduções, doravante empregaremos os seguintes sobrenomes do tradutores (Gama Kury, Rocha Pereira e Torrano).

\section{ANÁLISE DAS PASSAGENS TEXTUAIS}

No contexto do prólogo, a Ama apresenta a figura de Medeia sob um aviso: Cuidado! Medeia não sucumbiu. Ela reagirá. O verso 38 é traduzido por Torrano como "Grave é o espírito, nem suportará maus tratos [...]”. A primeira parte do verso é traduzida por Gama Kury com a expressão "coração impetuoso". Trata-se de um espírito perigoso, como ressalta a tradução de Rocha Pereira. O adjetivo barys, derivado da mesma raiz do verbo bareo, indica "tornar ou ser pesado", "sobrecarregado", "estar pesado de dor", enquanto phren significa "toda membrana que envolve um órgão", "a envoltura do coração", "a envoltura do fígado", "membrana de uma víscera", "entranhas", “coração". "Espírito perigoso" (bareia gar phren) implica um coração pesado de dor. Alguém assim é temível, capaz de fincar um punhal no próprio fígado. Nesse caso, o termo hepar pode traduzir a sede da cólera. Ainda no verso 44, diz a Ama que "quem moveu o seu ódio" (Rocha Pereira) não "celebrará facilmente bela vitória" (Torrano).

O ódio que governa Medeia a animaliza. A descrição ocorre na segunda parte do Prólogo, mais precisamente na última participação da Ama antes da primeira manifestação da protagonista. O contexto trata da intervenção da Ama, no sentido de alertar os filhos do casal Jasão/Medeia quanto ao perigo de se aproximarem da mãe. A rigor, trata-se de um pedido ao escravo pedagogo nos versos 89-92: "Ide, ó filhos, para dentro de casa, que lá tudo estará bem. E tu conserva-os à parte o mais que for possível, e não te aproximes da mãe em delírio; que eu já a vi olhá-los com olhos bravos de touro, que vai fazer algo de terrível [...]” (Rocha Pereira). Gama Kury enfatiza em sua versão o olhar feroz da esposa traída: “[...] mas ela nos olha, a nós, criadas, com o olhar feroz de uma leoa que teve filhotes [...]". O desespero, na visão da Ama, é tão evidente que na versão de Rocha Pereira recebe o nome de "delírio". Torrano, por sua vez, encontra para a expressão metri dysthymoumene o correspondente em português "mãe mal-animada". A expressão sugere que Medeia está sob um ímpeto tal que a descrição mais aproximada é a de um olhar de touro bravo pronto para atacar.

As animalizações podem ser consideradas uma espécie de extensão do domínio da cólera. Contudo, tomo tais animalizações, a despeito do estreito vínculo com a noção de ira, a partir de um campo semântico mais específico. Desta feita, o que melhor indica a 
animalização é o termo agrios, que pode ser traduzido como "feroz" ou "selvagem". As referências a animalizações ocorrem quatro vezes. A primeira se encontra no verso 103 . No verso referido, agrion aparece qualificando a palavra ethos, resultando na expressão "feroz caráter" (agrion ethos), para designar o caráter de Medeia. A expressão foi traduzida por Gama Kury como "gênio selvagem” e em Rocha Pereira como a síntese das duas primeiras traduções, isto é, "caráter selvagem". A expressão agrion ethos está no mesmo contexto informado por ocasião da figura de animalização extraída do Prólogo. Trata-se do alerta dirigido às crianças em relação ao perigo que a mãe representa. O cuidado da Ama se funda no receio de que a cólera de Medeia recaia sobre amigos, e não inimigos (v. 94-95).

O caráter selvagem de Medeia, que, ainda no verso 103, recebe um complemento, a saber, "hedionda natureza de espírito implacável" (Torrano), abre a segunda participação da personagem. Nos versos 112-114, encontramos a justificativa factual dos temores da Ama. O termo stygeran, que no verso 103 qualifica a natureza de Medeia, é novamente empregado pelo poeta no verso 113. Dessa feita, a palavra é destinada à fala da própria Medeia. Numa cena que mistura lamento e imprecação, ela diz, referindo-se a si mesma: "Ó malditos filhos de hedionda mãe, pereçam com o pai e desapareça toda a casa!” (Torrano). Admitindo-se hedionda, pelo menos nas circunstâncias em que se encontra, Medeia traduz nessa cena, ainda que apenas na ordem da palavra posta sob a forma de lamento, o olhar animalesco sobre os filhos, correspondente ao depoimento da Ama no verso 92.

Nos versos 187-188, a Ama novamente se refere a sua senhora empregando figuras de animalização. Na versão de Gama Kury, o trecho é traduzido da seguinte maneira: “[...] mas ela nos olha, a nós criadas, com o olhar feroz de uma leoa que teve filhotes [...]”. Embora o tradutor apresente claramente a animalização da personagem, o referido trecho ganha maior ênfase nas versões de Torrano e de Rocha Pereira. O que ocorre nessas traduções é uma espécie de dupla animalização, a saber, o emprego das figuras de leoa e touro. Ocorre dupla comparação. O olhar de Medeia é comparado ao olhar de leoa parida, olhar que traduz a iminência de um ataque de um touro quando olha o servo que se aproxima. Diz a versão de Torrano: "com o olhar de parida leoa qual touro olha o servo que se aproxime a proferir palavras". Aproximar-se de uma Medeia animalizada não é uma tarefa fácil. A Ama, atendendo ao pedido do Coro (v. 184-186), alerta acerca do provável insucesso quanto à incumbência de ele trazer à presença a esposa desditosa. É aí que a animalização fica mais evidente ainda. Nas palavras de Rocha Pereira: "Assim farei; mas temo não convencer a 
minha senhora; mas este penoso favor eu te concedo, apesar de o seu olhar de leoa que pariu ser bravo como um toiro para os servos, quando algum, p'ra falar-lhe, se aproxima".

Após a segunda participação da personagem de Medeia, a Ama (v. 115 - 117) diz: "Mísera! Que parte os filhos têm nos erros do pai? Por que os odeias (echtheis)? (Torrano). Nos versos 103, 113 e 147, o termo empregado é stygeras ou, a rigor, stygeran (v. 103), stygeras (v. 113) e stygeran, novamente no verso 147. Nessas três ocorrências, a palavra é traduzida (Torrano) por "hediondo" ou "hedionda". "Hedionda natureza" (stygeran te physin) no verso 103, "hedionda mãe" (stygeras matros) no verso 113 e "hedionda vida" (biotan stygeran) no verso 147. Vale ressaltar que a ocorrência do referido termo se dá tanto na versão grega utilizada por Torrano quanto na versão grega estabelecida pela editora ateniense Kaktos. As versões de Gama Kury e de Rocha Pereira traduzem, no entanto, os termos stygeran, ou stygeras, como "odioso" ou "odiosa".

O ódio que domina o coração - capaz de motivar atos hediondos - engendra o desejo de aniquilar o marido, que descaradamente argumenta que desposará a jovem filha do rei do Corinto como estratégia para futuramente beneficiar os filhos que ele tivera com Medeia. Por isso a esposa traída quer ver Jasão e a noiva reduzidos a pedaços.

A partir do verso 214 até o final da peça, os termos cholos e orge ocorrem doze vezes, embora interessa oito ocorrências, quando se referem ao comportamento de Medeia.

O termo possui importância cabal na tentativa do marido de se isentar da responsabilidade pela destruição do lar - imputada a ele por Medeia. "Não é esta a primeira vez, mas já muitas eu vi como a cólera violenta é um mal irremediável” (Rocha Pereira). Para Jasão, Medeia é incapaz de domesticar sua impulsividade. Nesse sentido, a versão de Gama Kury é bastante oportuna: "Esta não é a vez primeira. Já senti em várias ocasiões que o ânimo irascível é um mal insuportável”. A atribuição de um ânimo intratável está de acordo com a descrição da Ama no verso 38 (bareia gar phren), cuja expressão é traduzida por Torrano como "Grave é o espírito".

Portadora de um "espírito perigoso" (Rocha Pereira), Medeia é a causa do exílio a que está na iminência de ser submetida (v. 450). A alma irascível fez com que ela não se contivesse diante da vontade do soberano: "serás expulsa do país por palavras infelizes" - é o que afirma Jasão. Nesse sentido, a referência de Jasão à causa da expulsão de sua esposa é ao termo "cólera". A ocorrência dos termos orge e cholos compreende a seguinte distribuição: a) a Ama emprega os termos cinco vezes (v. 94, v. 99, v. 121, v. 129, v. 172); b) nas palavras do Coro, os termos ocorrem quatro vezes (v. 176, v. 520, v. 637, v. 1266); c) na fala de Jasão 
cinco vezes (v. 447, v. 456, v. 590, v. 615, v. 909); d) empregados por Medeia, três vezes (v. 590, v. 870, v. 898); e) na fala do Mensageiro, duas vezes (v. 1150, v. 1172).

O comportamento colérico, atribuído a Medeia, gera cólera também nos outros. Tratase do verso 455, no qual Jasão enfatiza o seu esforço de "dissipar as iras dos reis enfurecidos" (Rocha Pereira), enquanto Medeia, "a dizer mal dos soberanos" (v. 47-48 - Rocha Pereira), dera causa ao exílio prestes a acontecer.

O argumento de Jasão é, no entanto, passível de questionamento, pois em nenhum momento Medeia enfrenta diretamente Creonte. Quando Jasão diz no verso 447 "tu não folga loucuras, sempre a dizer mal dos tiranos" (Torrano) trata-se muito mais de uma estratégia de argumentação. Após a longa réplica de Medeia (v. 465-519), o Coro se manifesta no verso 520: "Terrível e difícil de curar é a cólera que lança amigos contra amigos e os separa!" (Gama Kury). Nesse trecho, o termo empregado é novamente orge. Como no verso discutido anteriormente, o termo é posto aqui de uma forma generalizante, não indicando diretamente Medeia como referente da cólera. Ainda assim, podemos atribuí-lo a Medeia em função do contexto. A impressão que se tem é a de que o Coro interrompe a cena para inferir e, ao mesmo tempo, predizer que, sob o estado de ira, não pode haver consenso, ainda que seja uma disputa entre supostos amigos (philoi).

De fato não há consenso. Os logoi não se ajustam, pois ao que parece nos versos 589590, as palavras veiculam a ira da esposa - pelo menos é o que diz Jasão: "Tu nem agora ousas despedir do coração a grande cólera" (Torrano). A expressão kardias megan cholon foi traduzida por "grande ira do coração" (Rocha Pereira). A despeito da beleza da argumentação de ambos os lados, o referido verso sugere um debate que, curiosamente, é lógico-racional, mas movido pelos sentimentos. Nesse sentido, a versão de Gama Kury é bastante oportuna: "tu que, neste momento, nem podes frear esse rancor terrível de teu coração". A cena parece ser dominada pelo rancor, especialmente em relação a Medeia.

O término do embate entre Jasão e Medeia supõe que a ira domina a cena do início ao fim. Segundo Cidre (1998, p. 59, tradução nossa),

As variações lexicais primitivas próprias da noção de cólera são dois: cholos e orge. Em primeiro lugar, cholos, como Chantraine aponta [no Dictionary Etimological de la Langue Grecque, Klincksieck, Paris, 1968-1980, p. 1267-1268], que implica "amargura" e "rancor", tem como dualidade básica a noção médica de "bile" e a noção psicológica de "humor". Na Ilíada tais noções aparecem como "ardor no combate" e na literatura pós-clássica indica "veneno de plantas ou serpentes". O segundo termo em questão, orge, conforma a cólera como "paixão". Nenhum 
registro dessa sema é encontrado em Homero; já em Hesíodo significa "modo de ser, comportamento cambiante das mulheres. $^{2}$

O verso 898 diz: "Tenhamos trégua e o rancor é revogado" (Torrano). A cena tem seu início com a demonstração de sensibilidade por parte de Jasão ao atender o chamado de Medeia: "Ao teu chamado venho. Apesar da tua hostilidade, não deixarás certamente de ser servida. Mas quero ouvir o que pretendes de novo da minha parte, ó mulher" (Rocha Pereira). A esposa roga pelo perdão do marido, como traduz Rocha Pereira: "Rogo-te, Jasão, que perdoes as minhas palavras. É natural que suportes as minhas iras, dadas as muitas provas de amor que traçamos" (v. 869-871). Assumir a ira é a condição para o pedido de perdão e, consequentemente, converte-se no sinal do arrependimento: "Miserável, que insânia é esta, e que hostilidade para com quem me quer bem?” (v. 875-876 - Rocha Pereira). Em relação ao trecho, observa Cidre (1998) que é notável como Medeia assume o arrependimento como uma espécie de ardil para levar a cabo o plano de vingança, pois no contexto de um pedido de perdão, faz sentido dizer que não existe mais rancor (v. 898). Mas ela desloca a particularidade da situação que provocara o estado de ira para a generalidade do feminino, concordando, assim, com o trecho proferido por Jasão nos versos 567-575. Diz o trecho (TORRANO): “Está mal tramado? Não o dirias, se não te afligisse o leito. Chegais a tanto que com a retidão do leito, vós, mulheres, credes tudo ter. Se, aliás, acontece infortúnio no leito, o mais útil e o mais belo tomais pelo mais hostil. Procriassem de outro modo os mortais e não houvesse gênero feminino, assim os mortais não teriam nenhum mal!”. Trata-se de dizer o que Jasão gostaria de ouvir, o que resulta na imediata aprovação dele. Depois de uma breve intervenção do Coro (v. 906-907), diz Jasão empregando, diferentemente de Medeia, o termo orgas: "Isso louvo, ó mulher, e aquilo não censuro. Porque é natural que o sexo feminino se enfureça contra os maridos [quando eles contraem núpcias estranhas]. Mas o teu ânimo mudou para melhor e, embora só com o tempo, reconheceste a decisão que prevaleceu. Esse procedimento é de mulher sensata" (Rocha Pereira).

Para a Plateia, tanto quanto para o Coro, o fato de Medeia forjar o arrependimento, assumindo-se como colérica, confirma o domínio da ira, ainda que esta seja ofuscada pela

\footnotetext{
${ }^{2}$ Los lexemas rastreados privativos de la cólera son dos: cholos e orge. Em primer lugar, cholos es, como lo indica Chantraine [Dictionaire Etymologique de la Langue Grecque, Klincksieck, Paris, 1968-1980, pp. 12671268], la cólera que implica 'amargura' y 'rencor' teniendo a la vez una dualidad básica, la noción médica de 'bilis' y la noción psicológica de 'humor'. Em Ilíada aparece como 'ardor en el combate' y en la literatura postclásica pasa a ser 'veneno de plantas o serpientes'. El segundo término en cuestión, orge, conforma la cólera en tanto 'pasion'. No se hallan registros de este sema en Homero; en Hesíado significa 'manera de ser, comportamiento cambiante de la mujer.
} 
razoabilidade dos argumentos. A última ocorrência diz respeito ao termo cholos no verso 1266. Trata-se do comentário do Coro acerca da terrível cena na qual Medeia persegue os filhos no interior da casa para executá-los. A fala do Coro é uma fusão de espanto, lamento e indignação. Ele atribui a Medeia um estado quase de possessão quando diz: "Por que, desgraçada, a ira pesada na alma te cai e o crime hostil vem? (Rocha Pereira). A inferência possível nesse momento é que, a despeito das razões oferecidas por Medeia para punir o marido traidor e aquele que lhe deu a filha para ser desposada, somente alguém sob o domínio da ira poderia executar os próprios filhos.

\section{CONSIDERAÇÕES FINAIS}

Em face das ocorrências de animalização como expressão de pensamentos e ações movidos ao ódio, cólera, ira, entre outros sentimentos que compõem o domínio irascível da alma, só se pode concluir pela afirmação de que forças irracionais movem a protagonista, o que não quer dizer que o texto de Eurípides possibilite a construção de cenas marcadas pelo confronto de razões ou pela maquinação racional. Mas o que parece ter sido demonstrado nas considerações acima é que essas forças que movem Medeia não podem simplesmente ser genericamente reduzidas à figura de um comportamento patético.

As animalizações são importantes nuanças ou desdobramentos de uma alma repleta e, portanto, dominado pela ira. Essas figuras, tais como touro e leoa, servem de aviso acerca de ações iminentes, indicando o caráter ativo da ação. Nesse sentido, compreende-se por que o poeta não empregou o termo pathos para designar a "posição" de Medeia no desenvolvimento do drama. E por mais paradoxal que pareça, a neta do Sol faz da força do irracional o motivo que justifica o cálculo racional. No final da peça, ela goza a vitória sem perder o estatuto da ação descrito - quase como uma didascália - pela Ama no prólogo: "Depois disto, chama-se leoa, se quiseres [chama-me Cila, a que habita o rochedo tirrénico], que o teu coração, eu atingi como cumpria. (v. 1351-1360 - Rocha Pereira).

\section{REFERÊNCIAS}

CIDRE, Elsa Rodríguez. Las cóleras en la Medea de Eurípides. Ciudad de Mexico: Nova Tellus, 16-2, 1998.

EURÍPIDES. Medeia. Tradução Maria da Gama Kury. Rio de Janeiro: Zahar, 2003. 
EURÍPIDES. Medeia. Tradução Jaa Torrano. Edição Bilingue. São Paulo: Hucitec, 1991.

EURÍPIDES. MHAEIA. Atena: Kaktoz, 1992.

EURÍPIDES. Medeia. Tradução Maria Helena da Rocha Pereira. Coimbra: JNICT, 1996.

FERÉZ, Juan Antonio López. Algumas notas sobre la Medea de Eurípides. In: FIALHO, Maria do Céu (coord.). Bajo el signo de Medea. Sob o signo de Medeia. Coimbra: Universidad de Valladolid, 2006.

FIALHO, Maria do Céu. A Medeia de Eurípides e o espaço trágico de Corinto. In: FIALHO, Maria do Céu (coord.). Bajo el signo de Medea. Sob o signo de Medeia. Coimbra: Universidad de Valladolid, 2006. 